\title{
PEMANFAATAN APLIKASI MOBILE BERBASIS IOS DALAM MENUNJANG USAHA WEDDING ORGANIZER
}

\author{
Nur Ani'; Muhammad Rizky Novaldi²; Muhamad Ega33; Tio Mafaza4 \\ Program Studi Ilmu Komputer ${ }^{1}$ \\ Universitas Mercubuana \\ https://www.mercubuana.ac.id \\ nur.ani@mercubuana.ac.id11,41815120105@student.mercubuana.ac.id², \\ 41815120094@student.mercubuana.ac.id ${ }^{3}$, 41815120052@student.mercubuana.ac.id 4
}

\begin{abstract}
Everyone wants to make their wedding receptions a very special day and give a moment that will not be forgotten in his life, so that the preparation and planning are ripe in making a plan to Provide the required results. But such high activity and mobility are a constraint to prepare such an important event that it does not maximize what is planned. PT H2O Planner is one of the wedding organizer who currently wants to improve the quality of the service provided. By providing mobile-based applications as one of the media in offering the services provided. PlanYourDays is a mobile based application created based on the needs of PT H2O Planner, using the prototype development method in the creation of this application. So that the application is produced according to the needs and desires of PT H2O Planner and can answer the problems of activity and mobility One obstacle in preparing for a wedding.
\end{abstract}

Keywords:, Mobile Application, Pieces ,Prototype Model, Wedding Organizer.

Intisari- Setiap orang ingin menjadikan acara resepsi pernikahannya menjadi hari yang sangat special dan memberikan momen yang tidak akan terlupakan dalam hidupnya, sehingga diperlukannya persiapan dan rencana yang matang dalam membuat suatu perencanaan untuk memberikan hasil yang dibutuhkan. Tetapi aktivitas dan mobilitas yang begitu tinggi menjadi kendala untuk mempersiapkan acara yang begitu penting sehingga tidak memaksimalkan apa yang sudah direncanakan. PT H2O Planner adalah salah satu wedding organizer yang saat ini ingin meningkatkan kualitas dari pelayanan yang diberikan. Dengan menyediakan aplikasi berbasis mobile sebagai salah satu media dalam menawarkan jasa yang diberikan. PlanYourDays adalah aplikasi berbasis mobile yang dibuat berdasarkan kebutuhan dari PT H2O Planner, dengan menggunakan metode pengembangan prototype dalam pembuatan aplikasi ini. Sehingga aplikasi yang dihasilkan sesuai dengan kebutuhan dan keinginan dari PT H2O Planner serta bisa menjawab permasalahan dari aktivitas dan mobilitas yang tinggi sebagai salah satu kendala dalam mermpersiapkan acara pernikahan.

Kata Kunci: Aplikasi Mobile, Pieces ,Model Prototype, Wedding Organizer.

\section{PENDAHULUAN}

Peningkatan jumlah pengguna internet di Indonesia mendorong pelaku bisnis menyediakan layanan secara online, baik melalui penggunaan website maupun aplikasi mobile. Menurut data dari Google insight 2019, Pertumbuhan ekonomi berbasis internet (e-commerce) di Indonesia merupakan yang tertinggi dan tercepat di kawasan Asia Tenggara (Google, Temasek, \& Bain \& Company, 2019). Penggunaan perangkat bergerak seperti telepon pintar (smart phones) atau biasa disebut telepon bergerak (mobile phones) semakin memberikan kemudahan bagi pengguna untuk melakukan transaksi secara online. Dengan kemudahan menu transaksi yang tersedia dan kegunaan aplikasi yang tinggi dapat meningkatkan keinginan pelanggan melakukan transaksi online (Ani \& Noprisson, 2018).

Salah satu fungsi yang banyak digunakan perangkat mobile phones adalah untuk mencari informasi, seperti halnya pencarian informasi mengenai layanan pengaturan pernikahan (wedding organizer). Dengan kesibukan yang ada saat ini, banyak calon pengantin melaksanakan pernikahan dengan bantuan perusahaan wedding organizer untuk membantu mereka merencanakan acara pernikahannya. Dengan tersedianya informasi secara online mengenai penyelenggara layanan wedding organizer tentu akan memudahkan calon pengantin dan bagi penyedia layanan juga dapat meningkatkan jangkauan pemasarannya (Sofian \& Solihin, 2018).

Penelitan mengenai pembangunan aplikasi untuk layanan wedding organizer telah dilakukan sebelumnya, seperti yang dilakukan oleh Taniah (2017), dengan melakukan analisa proses bisnis dari sebuah wedding organizer dan kemudian dari 
hasil analisa tersebut diperlukan sebuah sistem berbasis web untuk membantu meningkatkan efisiensi proses bisnis yang sudah berjalan (Taniah \& Harjunawati, 2017). Akan tetapi aplikasi yang dibuat belum memiliki referensi foto dari acara yang sudah berlangsung dan belum tersedianya fitur penilaian terhadap vendor yang ada. Sehingga dapat menjadi kekurangan bagi sisi pelanggan jika terjadi hal yang tidak diinginkan.

Selanjutnya penelitian yang dilakukan oleh Apriyanti (2017), pada penelitian tersebut peneliti menyimpulkan permasalahan yang dialami oleh wedding organizer tersebut adalah pada metode memberikan informasi tentang paket pernikahan hingga tips dalam pernikahan. Lalu dari analisa tersebut peneliti memutuskan untuk membuat sebuah aplikasi mobile berbasis android untuk mengatasi permasalahan tersebut (Apriyanti et al., 2017). Sama seperti penelitian sebelumnya, aplikasi tersebut belum memiliki fitur rating terhadap vendor. Sehingga menjadi concern bagi customer saat ingin memilih vendor karena tidak memiliki history penilaian.

Berdasarkan dua penelitian sebelumnya yang membahas tentang perancangan aplikasi wedding organizer berbasis web dan android. Peneliti bermaksud untuk membuat aplikasi berbasis mobile IOS dengan mengambil studi kasus pada PT H2O Planner. Pada proses bisnis sebelumnya yang dilakukan oleh PT H2O Planner secara manual yaitu dengan menemui calon user secara langsung saat ingin memberi informasi terkait jasa yang ditawarkan dengan memberikan brosur maupun presentasi singkat kepada calon user. Lalu calon user yang ingin mendapatkan informasi tentang jasa yang disediakan oleh PT H2O Planner harus meluangkan waktunya untuk bertemu langsung dan melihat brosur serta mendengarkan presentasi singkat dari pihak PT H2O Planner tentang jasa yang ditawarkan. Lalu ketika user ingin menggunakan jasa dari PT.H2O, user harus menghubungi PT H2O Planner dan membuat janji untuk booking jasa yang diinginkan. Dengan proses bisnis yang terjadi, berpotensi terjadinya miss information yang disampaikan oleh PT H2O Planner maupun yang diterima oleh user. Lalu sulit dalam menyesuaikan waktu luang antara PT H2O Planner dan user sehingga sering terjadi penguluran waktu yang berujung pada pembatalan pertemuan sehingga menyebabkan resiko kerugian berupa hilangnya kesempatan mendapatkan keuntungan (Setiawan, 2018).

Berdasarkan pembahasan sebelumnya tentang proses bisnis yang dijalankan oleh PT H2O Planner. Peneliti bermaksud untuk membantu meningkatkan efisiensi proses bisnis yang dijalakan oleh PT H2O Planner dengan membuat aplikasi mobile berbasis IOS diharapkan dapat memudahkan PT H2O Planner dalam menjalankan bisnisnya. Penelitian ini menggunakan metode prototype sebagai metode dalam pembuatan aplikasinya. Prototype adalah sebuah metode pengembangan sistem yang potensial bagi pengembang dan user (Rosi Subhiyakto \& Wahyu Utomo, 2017). Sehingga aplikasi yang dibuat sesuai dengan kebutuhan user baik dari sisi fitur maupun design. Sebelum aplikasi ini dibuat, peneliti melakukan diskusi terlebih dahulu dengan PT H2O Planner untuk membahas kebutuhan fitur maupun design yang diinginkan. Proses diskusi tidak berlangsung lama, karena saat diskusi berlangsung peneliti memberikan demo singkat tentang aplikasi yang sudah dirancang sebelumnya. Setelah peneliti memberikan demo aplikasi, barulah pihak PT H2O Planner memberikan feedback terhadap fitur dan design yang diingkan.

Plan Your Days adalah aplikasi yang dibuat berdasarkan hasil diskusi dengan PT H2O Planner yang menyesuaikan dengan kebutuhan fitur dan design yang diinginkan. Dengan dibuatnya aplikasi Plan Your Days, diharapkan dapat membantu PT H2O Planner dalam menjalankan bisnisnya dengan lebih efisien karena telah mendapatkan peningkatan pada proses bisnisnya.

\section{METODE PENELITIAN}

\section{Pengumpulan Data}

Penelitian ini menggunakan metode observasi, wawancara, studi pustaka untuk memperoleh hasil yang mendukung pada pembuatan aplikasi PlanYourDays serta sesuai dengan kebutuhan perusahaan terhadap aplikasi yang akan dibuat. Dalam pengumpulan data, berikut ini merupakan metode yang penulis gunakan:

\section{a. Riset Lapangan (observasi)}

Pada metode ini peneliti melakukan suatu pengamatan yang secara langsung kepada pasangan yang ingin menggunakan jasa PT H2O Planner untuk memahami proses apa saja yang di butuhkan dalam melakukan persiapan pernikahan serta memahami transaksi yang ada pada PT H2O Planner agar dapat memahami yang diperlukan dalam proses bisnis yang berjalan(Informasi, Margonda, \& Kusnadi, 2018).

\section{b. Wawancara}

Dalam metode ini penulis bertanya langsung kepada PT.H2O Planner. Selaku wedding organizer yang peneliti pilih untuk dijadikan studi kasus pada penelitian ini. Pada metode ini peneliti menampilkan prototype aplikasi yang sudah dibuat sebelumnya sebagai media untuk memberikan gambaran kepada perusahaan tentang aplikasi 
yang akan dibuat, apakah sudah sesuai dengan kebutuhan perusahaan. Setelah itu peneliti bertanya kepada perusaahan tentang hal-hal yang perlu ditambahkan atau dihilangkan pada aplikasi yang akan dibuat. Sehingga hasil akhir dari aplikasi sudah sesuai dengan kebutuhan perusahaan (Putra, 2018).

\section{c. Study Pustaka (Literatur)}

Dalam metode digunakan peneliti untuk memahami suatu yang ada dalam mendukung data yang telah didapat dari hasil observasi dan wawancara dengan cara membaca artikel jurnal, buku dan referensi-referensi lain yang mengacu pada tema penelitian yang berkaitan dengan aplikasi PlanYourDays (Natsir, 2016).

\section{Diagram Alir Penelitian}

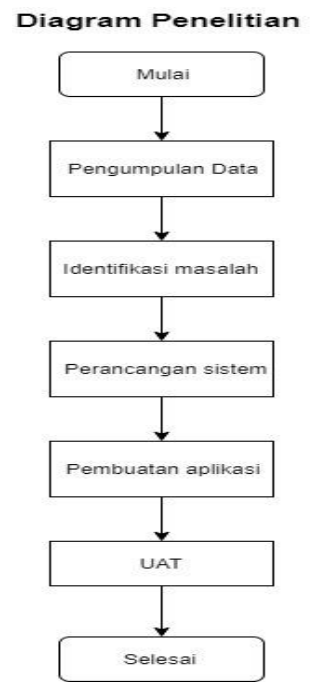

Sumber : (Ani, Novaldi, Ega, \& Mafaza, 2019)

Gambar 1 Diagram Alir Penelitian

Setiap alur dapat dijelaskan sebagai berikut:

\section{Pengumpulan Data}

Pada tahap ini peneliti melakukan demo aplikasi yang sudah dibuat sebelumnya sebagai prototype awal agar client memiliki gambaran yang jelas terhadap hasil aplikasi akhir yang akan dibuat. Setelah client melihat prototype aplikasi yang sudah peneliti buat, peneliti meminta feedback dari client terhadap prototype yang sudah dibuat. Apakah ada hal yang perlu ditambah atau dikurangi pada aplikasi yang akan dibuat (Syahputra \& Kurniawan, 2018).

\section{Identifikasi Masalah}

Setelah melakukan pengumpulan data dari feedback yang didapat melalui demo prototype kepada client, peneliti melakukan diskusi dengan team untuk menerapkan kebutuhan client terhadap aplikasi yang akan dibuat. Pada tahap ini peneliti melakukan kalibrasi terhadap proses bisnis yang sudah diterapkan oleh client ke dalam aplikasi yang akan dibuat.

\section{Perancangan Sistem}

Dari hasil diskusi dengan team terkait kebutuhan dan masukan tambahan dari client, dilakukan perancangan sistem, penyesuaian design dan rancangan database.

\section{Pembuatan Aplikasi}

Setelah sistem selesai dirancang, design sudah disesuaikan, dan rancangan database telah dibuat. Barulah masuk ketahap pembuatan aplikasi, dalam kasus ini peneliti sudah membuat prototype sebelum melakukan demo kepada client. Sehingga dilakukannya penyesuaian prototype sesuai dengan kebutuhan client.

\section{UAT}

Setelah aplikasi dibuat, peneliti menunjukan aplikasi yang sudah dibuat berdasarkan kebutuhan client. Jika aplikasi sudah dianggap sesuai maka aplikasi dapat diserahkan ke client. Jika belum sesuai peneliti melakukan revisi sesuai dengan kebutuhan client.

\section{HASIL DAN PEMBAHASAN}

Metode yang digunakan dalam penelitian ini yaitu dengan menggunakan model prototype. Hal ini bertujuan untuk mendapatkan feedback serta requirement dari user terhadap aplikasi. Lalu feedback dan requirement tersebut yang nantinya akan dikembangkan dalam pembuatan aplikasi

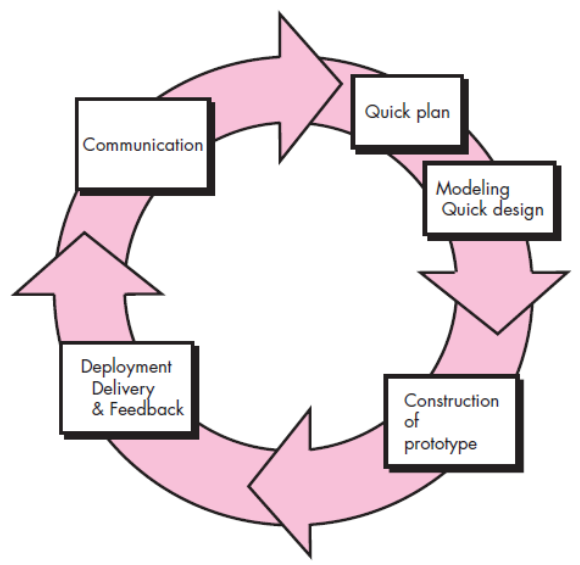

Sumber : (Suryn, 2014)

Gambar 2 Model Prototyping

berdasarkan gambar 2 yang menjelaskan tahapan pada prototype, pada tahap awal dalam proses prototype ini adalah dengan melakukan demo pada aplikasi yang sudah dibuat sebelumnya, demo aplikasi ini bertujuan agar user dapat memberikan 
feedback pada aplikasi yang sudah dibuat. Dari hasil tersebut kami melakukan pengumpulan data dari feedback yang kami dapat serta melakukan diskusi dengan team untuk menerapkan kebutuhan user terhadap aplikasi yang akan dibuat. Lalu melakukan perancangan kembali untuk menyesuaikan design dan fitur yang diinginkan oleh user dengan pembuatan prototype aplikasi. Setelah itu prototype didemokan kembali kepada user untuk meminta review dari hasil penyesuaian design dan fitur dari kebutuhan user, jika sudah sesuai maka dilakukan dengan pembuatan aplikasi.

\section{Communication}

Dalam fase ini user dan peneliti bertemu untuk berdiskusi tentang proses bisnis yang sedang berjalan dan kebutuhan terhadap fitur aplikasi yang akan dibuat.

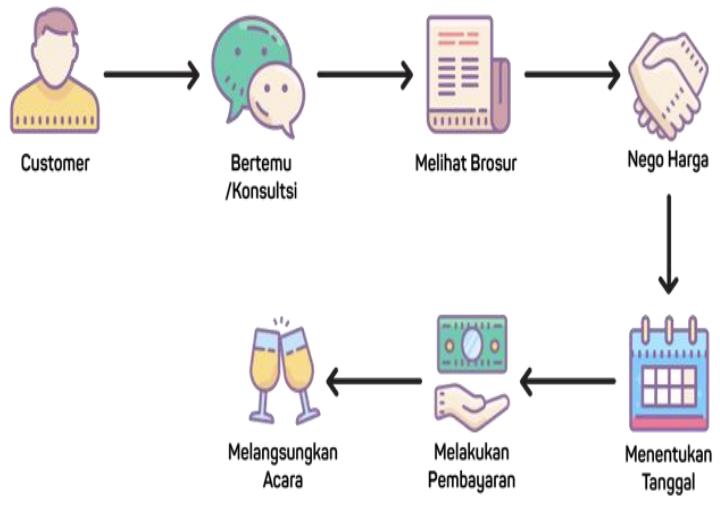

Sumber : ( Ani, Novaldi, Ega, \& Mafaza, 2019)

Gambar 3 Analisa Bisnis Sebelumnya

Gambar 3 adalah analisa proses bisnis yang sedang berjalan pada PT.H H2O. Untuk menggunakan jasa PT. H2O, calon pelanggan harus bertemu dengan pihak PT. H2O untuk melihat dan berdikusi tentang jasa apa saja yang disediakan oleh pihak W.O. Melihat katalog dari paket pernikahan secara langsung melalui brosur dan melihat pilihan vendor yang menjadi partner dari PT. H2O melalui brosur maupun presentasi singkat menggunakan laptop. Jika pelanggan memutuskan untuk menggunakan jasa dari PT. H2O dan memilih vendor, barulah dapat melihat rincian harga yang telah dihitungkan secara manual oleh pihak W.O.

\section{Quick Plan}

Setelah berdiskusi dengan PT. H20, peneliti melakukan identifikasi masalah menggunakan metode PIECES untuk memperolah dasar pokokpokok permasalahan terhadap sistem berjalan tersebut. Analisa tersebut dilakukan untuk memberikan solusi dari pokok permasalahan yang terdapat pada sistem berjalan (Gata \& Wardhana, 2017). Adapun hasil Analisa dan solusi adalah sebagai berikut:

Tabel 1 Tabel Analisa PIECES

\begin{tabular}{|c|c|c|}
\hline $\begin{array}{c}\text { Jenis } \\
\text { Analisa }\end{array}$ & Kendala & Solusi \\
\hline $\begin{array}{l}\text { Performan } \\
\text { ce }\end{array}$ & $\begin{array}{lr}\text { Diperlukan } & \text { waktu } \\
\text { bertemu } & \text { dengan } \\
\text { calon } & \text { pelanggan } \\
\text { untuk } & \\
\text { menyampaikan } \\
\text { informasi } & \text { tentang } \\
\text { pilihan } & \text { paket } \\
\text { pernikahan } & \text { dan } \\
\text { vendor } & \end{array}$ & $\begin{array}{lr}\text { Tersedianya } & \\
\text { informasi } & \text { paket } \\
\text { pernikahan } & \text { dan } \\
\text { vendor } & \text { yang } \\
\text { menjadi } & \text { partner } \\
\text { PT.H2O. } & \end{array}$ \\
\hline \multirow[b]{2}{*}{$\begin{array}{c}\text { Informatio } \\
n\end{array}$} & $\begin{array}{l}\text { Calon pelanggan } \\
\text { membutuhkan } \\
\text { referensi konsep } \\
\text { pernikahan } \\
\text { beragam. }\end{array}$ & $\begin{array}{l}\text { Tersedianya } \\
\text { Gallery } \\
\text { menampilkan } \\
\text { pilihan referensi }\end{array}$ \\
\hline & $\begin{array}{l}\text { Calon pelanggan } \\
\text { membutuhkan daftar } \\
\text { vendor yang menjadi } \\
\text { partner }\end{array}$ & $\begin{array}{l}\text { Tersedia modul } \\
\text { Vendor untuk } \\
\text { menampilkan } \\
\text { daftar partner yang } \\
\text { sudah } \\
\text { dikategorikan. }\end{array}$ \\
\hline \multirow[b]{2}{*}{ Economic } & $\begin{array}{l}\text { Dibutuhkan biaya } \\
\text { lebih untuk membuat } \\
\text { katalog berupa } \\
\text { brosur yang berisi } \\
\text { paket pernikahan } \\
\text { atau pilihan vendor. }\end{array}$ & $\begin{array}{l}\text { Dibuatkan aplikasi } \\
\text { yang dapat } \\
\text { menampilkan } \\
\text { informasi pilihan } \\
\text { vendor. }\end{array}$ \\
\hline & $\begin{array}{l}\text { Dibutuhkan biaya } \\
\text { lebih jika calon } \\
\text { pelanggan } \\
\text { melewatkan } \\
\text { beberapa informasi } \\
\text { seperti harga paket } \\
\text { atau biaya jasa dari } \\
\text { beberapa vendor } \\
\text { partner. }\end{array}$ & $\begin{array}{lr}\text { Dibuatkan } & \text { modul } \\
\text { yang menampilkan } \\
\text { daftar } & \text { partner } \\
\text { beserta } & \text { pilihan } \\
\text { harga } & \text { yang } \\
\text { tersedia. } & \text { Calon } \\
\text { pelanggan } & \text { bisa } \\
\text { menyesuaikan } & \\
\text { dengan budget. }\end{array}$ \\
\hline Control & $\begin{array}{l}\text { Pendataan pelanggan } \\
\text { dan daftar partner } \\
\text { masih dilakukan } \\
\text { secara manual, resiko } \\
\text { data lost }\end{array}$ & \begin{tabular}{lr} 
Tersedia & portal \\
admin & untuk \\
melakukan & control \\
dari sisi & aplikasi \\
dan menarik & data \\
dari & penguna \\
aplikasi & dan \\
pembaruan & dari \\
daftar partner yang \\
\multicolumn{2}{l}{ tersedia. }
\end{tabular} \\
\hline \multirow[t]{2}{*}{ Eficiency } & $\begin{array}{l}\text { Tingkat keberhasilan } \\
\text { dalam mendapatkan } \\
\text { pelanggan karena } \\
\text { calon pelanggan } \\
\text { sering melewatkan } \\
\text { beberapa informasi } \\
\text { yang disampaikan } \\
\text { secara lisan. }\end{array}$ & \begin{tabular}{lr} 
Dibuatkan & sebuah \\
\multicolumn{2}{l}{ aplikasi yang dapat } \\
menampilkan jasa \\
yang ditawarkan \\
oleh PT. H2O \\
sehingga calon \\
pelanggan dapat \\
melihat-lihat \\
langsung \\
$\begin{array}{ll}\text { aplikasi. } \\
\text { lada }\end{array}$ \\
\end{tabular} \\
\hline & $\begin{array}{l}\text { Membutuhkan waktu } \\
\text { saat menghitung } \\
\text { total biaya yang } \\
\text { harus dibayarkan } \\
\text { oleh calon pelanggan. }\end{array}$ & $\begin{array}{l}\text { Dibuatkan halaman } \\
\text { pada aplikasi yang } \\
\text { menampilkan total } \\
\text { biaya yang harus } \\
\text { dibayarkan dari } \\
\text { vendor yang dipilih. }\end{array}$ \\
\hline
\end{tabular}




\begin{tabular}{clrl}
\hline Jenis & \multicolumn{2}{c}{ Kendala } & \multicolumn{2}{c}{ Solusi } \\
Analisa & \multicolumn{2}{c}{ terjadi } & \\
& Sering & yang \\
& keterlambatan dalam & Aplikasi & yang \\
& memberi informasi & dibuat akan \\
kepada calon & menampilkan \\
& kervice & pelanggan terhadap & pilihan partner dan \\
& apa yang mereka & daftar harga yang \\
& tanyakan seperti & sesuai dengan \\
& daftar partner dan & budget yang sesuai \\
& harga paket. & & \\
\hline
\end{tabular}

Sumber : (Ani, Novaldi, Ega, \& Mafaza, 2019)

\section{Modeling Quick Design}

Setelah melakukan identifikasi masalah menggunakan metode PIECES dan mengumpulkan pokok-pokok kebutuhan yang akan diimplementasikan ke dalam aplikasi. Berdasarkan table 1 yang menjelaskan tentang analisa Pieces maka dari itu di perlukan 2 platform yang memiliki fungsi untuk mendukung admin dalam melakukan pengelolaan data serta memudahkan pembuatan laporan dan dibuatkannya aplikasi mobile yang memudahkan customer dalam melakukan pencarian vendor.

\section{Use Case Diagram}

Terdapat use case diagram pada rancangan sistem yang dibuat terdiri dari dua actor yaitu pembeli dan admin. Berikut gambar use case diagram pada rancangan aplikasi.

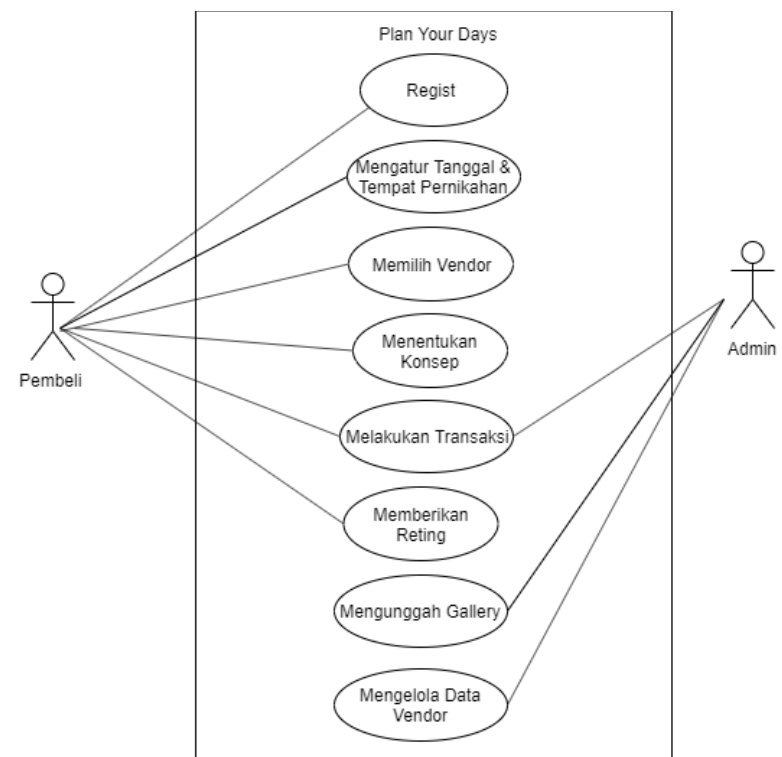

Sumber : ( Ani, Novaldi, Ega, \& Mafaza, 2019)

Gambar 4 Use Case Diagram

Berdasarkan gambar 4 use case diagram terdapat 8 use case dan 2 actor yang terdiri dari pembeli dan admin. Pembeli dapat regist dengan mengisi data seperti nama lengkap, alamat email, password serta konfirmasi password. Pembeli dapat mengatur tanggal dan tempat pernikahan. Pembeli dapat memilih vendor yang meraka ingin gunakan. Pembeli dapat menentukan konsep apa saja yang meraka gunakan. Pembeli dapat melakukan transaksi dengan melakukan pembayaran melalu rekening yang tertera pada aplikasi. Pembeli dapat memberikan rating setelah acara selesai lalu admin dapat melakukan pengelolaan data mulai dari melakukan input data vendor, melakukan update data vendor serta dapat menghapus data vendor. Admin dapat melakukan pengunggahan gallery acara yang telah selesai setelah acara agar dapat menjadikan referensi bagi pembeli. Admin dapat mengkonfimasi transaksi pesan kepada pembeli.

\section{Class Diagram}

Terdapat class diagram yang memiliki fungsi satu sama lain dalam penyimpanan data. Class Diagram tersebut terdapat 20 class diantaranya:

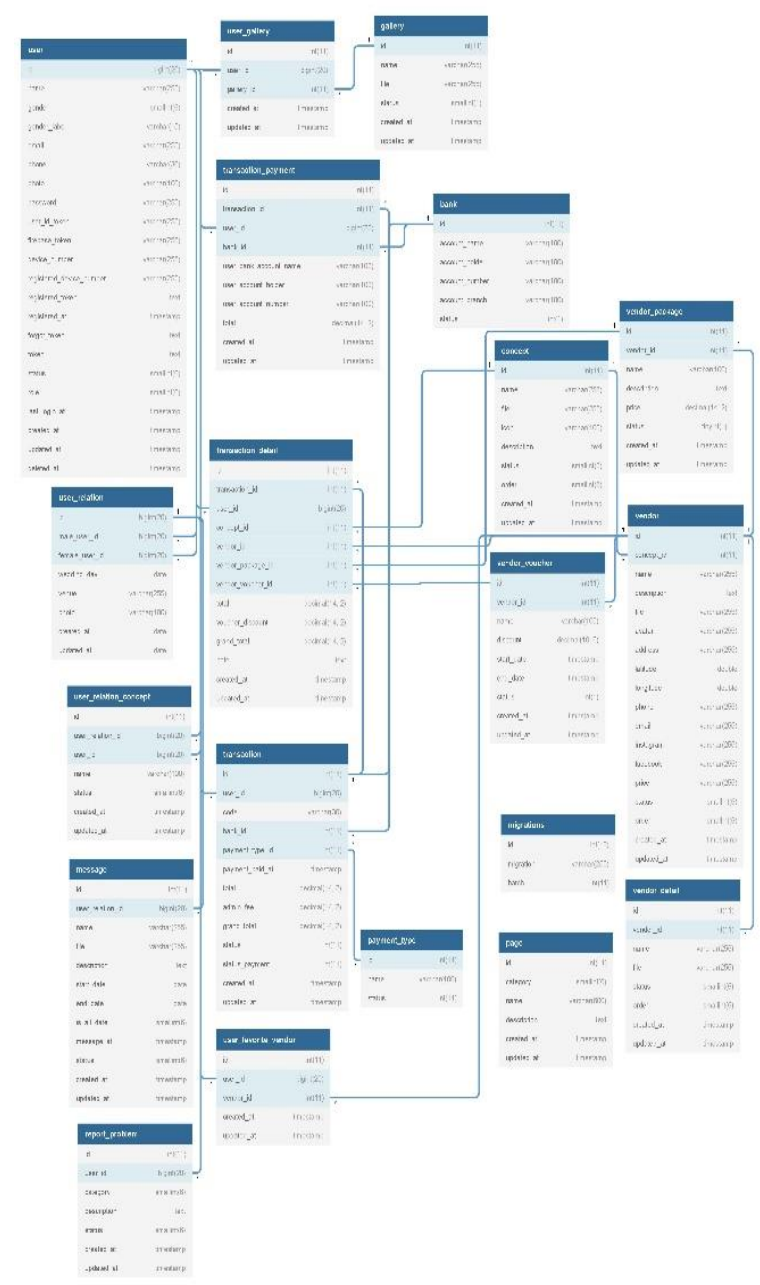

Sumber : ( Ani, Novaldi, Ega, \& Mafaza, 2019) Gambar 5 Class Diagram

\section{Construction of Prototype}

Pada tahap ini programmer mulai membuat aplikasi yang sesuai dengan kebutuhan user baik 
VOL. 5. NO. 2 FEBRUARI 2020

dari segi fitur maupun design. Berikut beberapa tampilan aplikasi yang akan dibangun:
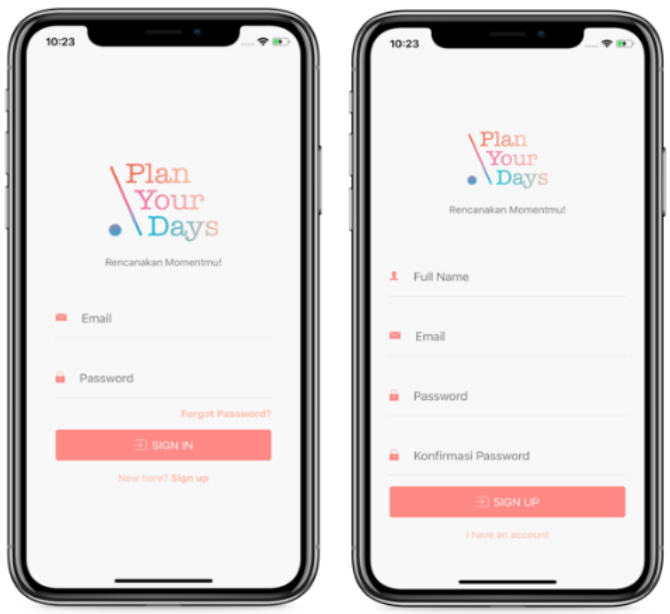

Sumber : ( Ani, Novaldi, Ega, \& Mafaza, 2019)

Gambar 6 Tampilan Halaman Login Dan Regist Aplikasi

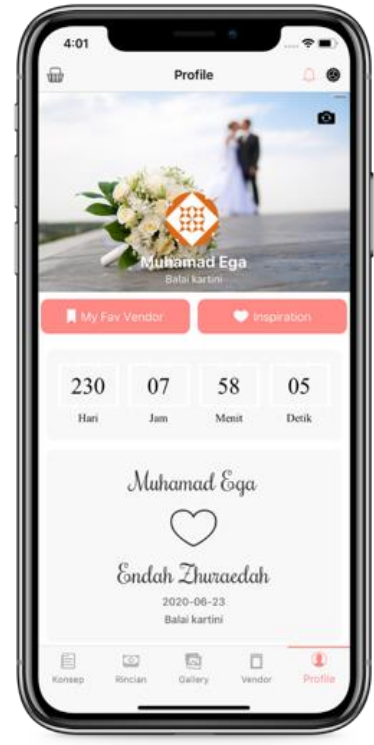

Sumber : ( Ani, Novaldi, Ega, \& Mafaza, 2019) Gambar 7 Tampilan Halaman Utama
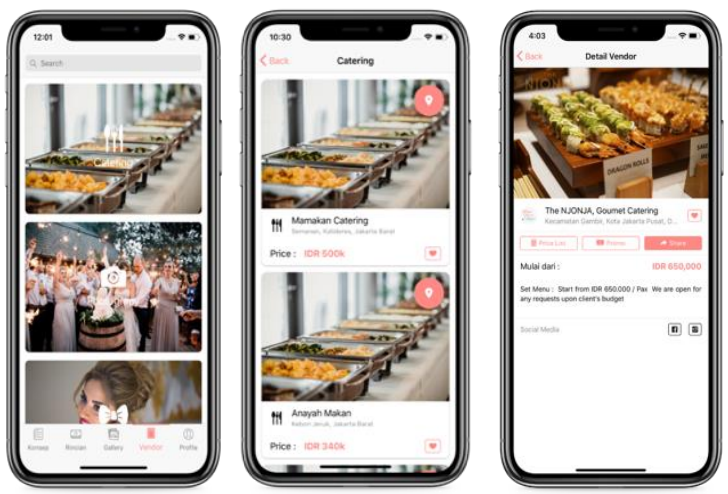

Sumber : ( Ani, Novaldi, Ega, \& Mafaza, 2019) Gambar 8 Tampilan Halaman Vendor

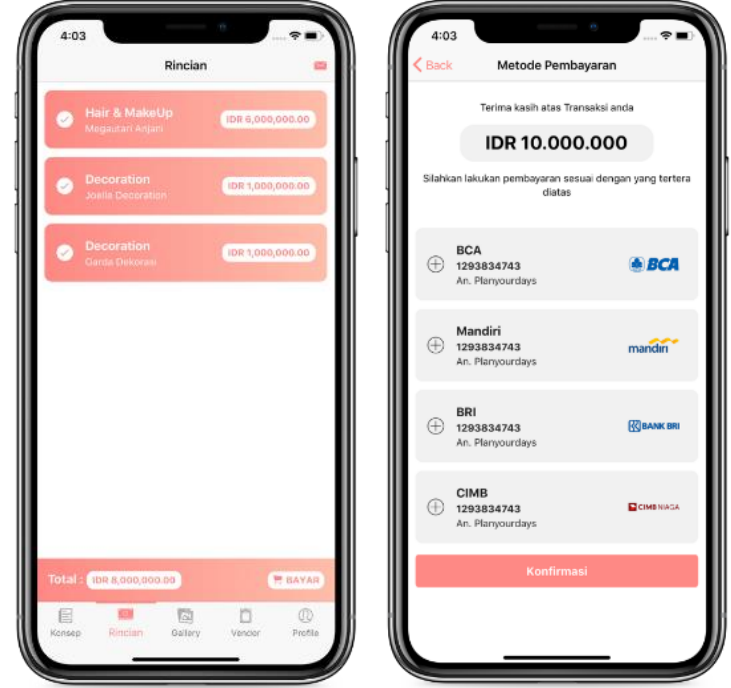

Sumber : ( Ani, Novaldi, Ega, \& Mafaza, 2019)

Gambar 9 Tampilan Halaman Rincian Transaksi

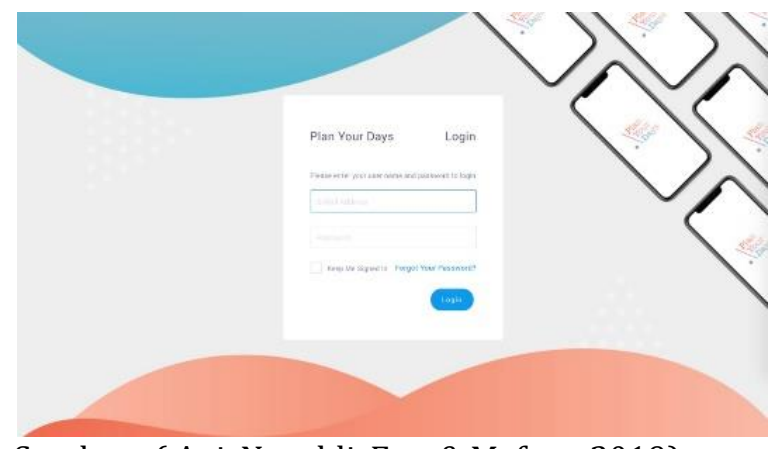

Sumber : ( Ani, Novaldi, Ega, \& Mafaza, 2019)

Gambar 10 Tampilan Halaman Login Dashboard

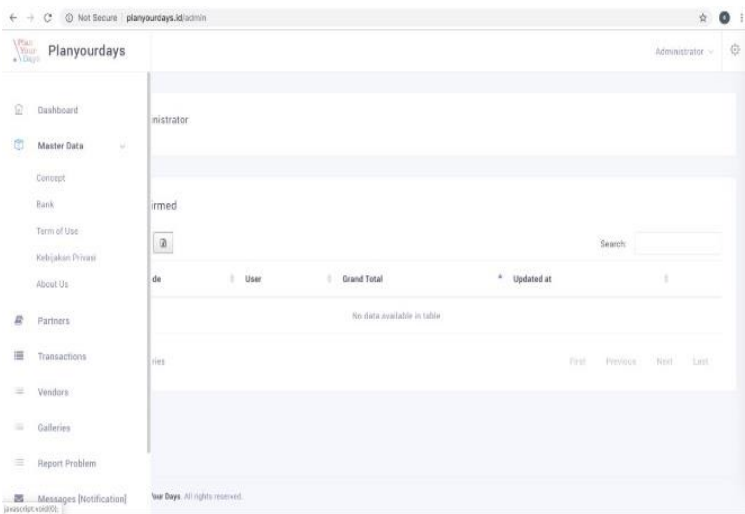

Sumber : ( Ani, Novaldi, Ega, \& Mafaza, 2019) Gambar 11 Tampilan Halaman Utama Dashboard

\section{Deployment Delivery \& Feedback}

Pada tahap ini programmer melakukan ujicoba terhadap aplikasi yang telah dibuat, apakah sudah 
sesuai dengan kebutuhan user dari segi fitur dan apakah aplikasi tersebut berjalan dengan baik. Setelah aplikasi selesai diuji oleh programmer barulah aplikasi didemokan kepada PT. H2O sebagai user yang akan menggunakan aplikasi ini dalam proses bisnisnya. Setelah team peneliti melakukan demo aplikasi, user juga melakukan ujicoba terhadap aplikasi yang telah dibuat agar peneliti mendapatkan feedback dari user terhadap aplikasi yang telah dibuat. Pada fase ini feedback dari user digunakan untuk melakukan perbaikan terhadap fitur maupun design aplikasi hingga user merasa aplikasi tersebut sudah sesuai dengan kebutuhannya.

\section{KESIMPULAN}

Dari hasil penelitian yang dilakukan untuk membuat aplikasi PlanYourDays menggunakan metode prototype, maka dapat disimpulkan bahwa aplikasi mobile dibutuhkan sebagai salah satu media dalam menjalan bisnis pada PT.H2O Planner. Aplikasi PlanYourDays memudahkan calon pengantin dalam melihat jasa yang ditawarkan oleh PT.H2O Planner dengan fitur fitur yang ada seperti gallery yang dapat membantu mencari referensi dari acara acara yang sudah berlansung, rating yang dapat memberikan informasi dari kelayakan vendor tersebut dan memudahkan admin dalam melakukan input informasi yang ingin ditampilkan pada aplikasi. Serta memudahkan admin dalam membuat laporan dari data data pelanggan dan vendor. Pengembangan dari aplikasi selanjutnya dapat ditambahkan personalization dari pengguna berdasarkan data demografi atau data pribadi calon pengantin untuk menentukan paket terbaik dan data lokasi dengan bantuan layanan Location Based Service (LBS) untuk menentukan lokasi gedung pernikahan yang terdekat dengan lokasi rumah calon pengantin.

\section{REFERENSI}

Ani, N., \& Noprisson, H. (2018). Consumer-level Factors of Purchase Intention in Online Travel Booking Application Based on Product Perspective, 3(7), 205-212.

Ani, N., Novaldi, M. R., Ega, M., \& Mafaza, T. (2019). Laporan Akhir Penelitian: PEMANFAATAN APLIKASI MOBILE SEBAGAI SOLUSI. Jakarta.

Apriyanti, N. A., Mubarak, A., Arief, A., Studi, P., Program, T., Teknik, S., ... Selatan, K. T. (2017). PERANCANGAN APLIKASI WEDDING ORGANIZER BERBASIS ANDROID PADA LILIAN WEDDING GALERY, 01(2), 88-93.
Gata, W., \& Wardhana, N. K. (2017). EVALUASI PERKULIAHAN MENGGUNAKAN METODE FRAMEWORK PIECES PADA UNIVERSITAS MERCUBUANA. JURNAL ILMU PENGETAHUAN DAN TEKNOLOGI KOMPUTER.

Google, Temasek, \& Bain \& Company. (2019). eConomy SEA 2019. Retrieved from https://www.thinkwithgoogle.com/intl/enapac/tools-resources/research-studies/economy-sea-2019-swipe-up-and-to-theright-southeast-asias-100-billion-interneteconomy/

Informasi, S., Margonda, J., \& Kusnadi, Y. (2018). APLIKASI SISTEM INFORMASI PEMESANAN PAKET PERNIKAHAN BERBASIS WEB ( Studi Kasus: SANGGAR LARAS WEDDING BOGOR ). Jurnal Teknologi Informatika \& Komputer, $4(2), 19-24$.

Natsir, M. (2016). Pengembangan Prototype Sistem Kriptografi Untuk Enkripsi Dan Dekripsi Data Office Menggunakan Metode Blowfish Dengan Bahasa Pemrograman Java. Jurnal Sistem Informasi (JSI), 6(2), 87-105.

Putra, M. (2018). Implementasi Network Attached Storage ( NAS ) Menggunakan Synology Disk Station Manager ( DSM 5.2 ) Untuk Optimalisasi Data Sharing Center. Jurnal Teknik Komputer AMIK BSI (JTK), IV(2), 3947. https://doi.org/10.31294/jtk.v4i2.3508

Rosi Subhiyakto, E., \& Wahyu Utomo, D. (2017). Analisis Dan Perancangan Aplikasi Pemodelan Kebutuhan Perangkat Lunak Menggunakan Metode Prototyping. Seminar Nasional Multi Disiplin Ilmu \& Call For Papers UNISBANK Ke-3(SENDI_U 3) 2017, (207), 5762.

Setiawan, R. (2018). Perancangan Elektronik Marketplace Event Organizer, (1), 247-254.

Sofian, J., \& Solihin, H. H. (2018). Pembangunan Aplikasi M-Wedding Sebagai Solusi Usaha Wedding Organizer. Jurnal Teknologi Dan Informasi, $8(2)$. https://doi.org/10.34010/jati.v8i2.1038

Suryn, W. (2014). Software Quality Engineering: A Practitioner's Approach. Software Quality Engineering: A Practitioner's Approach (Vol. 9781118592).

https://doi.org/10.1002/9781118830208 
Syahputra, A. K., \& Kurniawan, E. (2018). Perancangan Aplikasi Pemesanan Dan Pembayaran Berbasis Desktop Pada Percetakan UD. Azka Gemilang Menggunakan Metode Prototype. Seminar Nasional Raya (SENAR), 9986(September), 105-110.
Taniah, A. W., \& Harjunawati, S. (2017). Perancangan Sistem Informasi Transaksi Penyewaan Wedding Organizer Pada Cv.Denis Citra Mandiri Bekasi. Jurnal Ilmu Pengetahuan Dan Teknologi Komputer, 3(1), 59-64. 